\title{
3 boyutlu masa üstü yazıcı ile matematiksel bir modelden gerçek bir nesnenin dijital üretimi
}

\author{
Yılmaz GÜR ${ }^{1^{*}}$ \\ ${ }^{1}$ Balıkesir Üniversitesi Mühendislik Fak. Makina Müh. Böl., Çağış kampüsü, Balıkesir. \\ Gelis Tarihi (Recived Date): 13.06.2017 \\ Kabul Tarihi (Accepted Date): 04.10.2017
}

\section{Özet}

3 boyutlu yazıcı teknolojisi son yıllarda giderek yaygınlaştı ve bu da matematiksel modellerden, elle tutulabilir somut gerçek nesnelerin üretimini, şimdiye kadar hiç olmadığı kadar çok kolaylaştırdı. Bu çalışmanın amacı da eriterek üst üste yığma metodunu kullanan bir masa üstü 3 boyutlu yazıcı kullanarak, matematiksel denklemlerden yola çıkarak onların 3 boyutlu matematiksel modellerini oluşturmak ve oluşturulan bu modelleri de dijital olarak 3 boyutlu yazıcı ile üretmektir. Matematiksel denklemleri kullanarak 3 boyutlu matematiksel modellerin oluşturulması işlemi K3DSurf yazılımı kullanılarak gerçekleştirildi. 3 boyutlu matematiksel modeli oluşturan $x, y, z$ koordinatlarına ait veriler daha sonra üretimi gerçekleştirecek 3 boyutlu yazıcının tanıdı ̆̆ format olan “.obj” dosya formatına dönüştürüldü. MakerBot ${ }^{\circledR}$ firmasının MakerWare ${ }^{\mathrm{TM}}$ adlı katmanlara ayırma programı kullanılarak üretilecek model istenilen kalınlıktaki katmanlara ayrild, baskı kafasının $x$-y ekseni boyunca yapacağ hareketler hesaplattırlld ve bu veriler "gcode" formatına çevrilerek bir sd karta aktarıldı. Örnek çalışma olarak ise, Diamand denklemi, belirlenen sınır şartları arasında değerler verilerek 3 boyutlu matematiksel modeli oluşturuldu ve Flashforge Creator modeli masaüstü 3 boyutlu yazıcı ile dijital üretimi yapıldı.

Anahtar kelimeler: 3 boyutlu yazıcı, matematiksel modelleme, katmanlı üretim.

\section{Digital fabrication of a real object from a mathematical model by using 3D desktop printer}

\begin{abstract}
3-D printing technology is becoming widely available and can help to produce tangible solid physical objects from mathematical models much easier than ever before. The aim
\end{abstract}

*Yılmaz GÜR, ygur@balikesir.edu.tr, http://orcid.org/0000-0003-1709-1298 
of this paper is to construct mathematical models from mathematical equations and to fabricate real solid objects digitally from mathematical models by using a 3-D Fused Deposition Modelling (FDM) printer. Formation of $3 D$ mathematical models using mathematical equations was performed using K3DSurf software. The data for the $x, y, z$ coordinates that form the 3-D mathematical model are then converted to the ".obj" file format, which is the format recognized by the 3-dimensional FDM printer that will realize the fabrication. Using MakerBot ${ }^{\circledR}$ 's slicing software MakerWare ${ }^{\mathrm{TM}}$, the model to be fabricated is sliced into layers of desired thickness, movements of the printing head along the $x-y$ axis are calculated, and this data is transferred to a secure digital (SD) card in ".gcode" format. As a case study, a 3D mathematical model was obtained by assigning values to the Diamand equation between the boundary conditions, and it is digitally fabricated by using a FlashForge Creator desktop FDM 3D printer.

Keywords: $3 D$ printing, mathematical modelling, additive manufacturing.

\section{Giriş}

3 boyutlu yazıcı teknolojisi ilk olarak 1980'li y1llarda Charles Hull tarafindan stereolitografi adi ile geliştirildi [1-6]. 2009 yılında MakerBot isimli bir Amerikan şirketi üretimi demokratikleştirme düşüncesiyle, açık kaynak kodlu, eriterek biriktirme yöntemiyle (FDM) üretim yapan, $1.79 \mathrm{~mm}$ çaplı ABS veya PLA gibi plastik filmaşin malzemeleri kullanabilen, 3 boyutlu yazıcı MakerBot ${ }^{\circledR}$ 'u ve katmanlara ayırma yazılımı MakerWare ${ }^{\text {TM'i }}$ piyasaya sürdü [7]. 3 boyutlu yazıcılar hayatımızın her kesitini etkileyecek ve son derece karmaşık parçalar çok daha az atık ve daha az karbon salınımı ile üretilebilmesini sağlayacaktır [8]. 3 boyutlu yazıcılar sayesinde küçük boyutlardaki, az miktarda üretilecek olan ve son derece karmaşık ve girift parçaların üretiminde yaygın olarak kullanılacaktır $[9,10]$.

3 boyutlu yazıcılar matematiksel araştırmalarda ve matematik eğitiminde geometrik görselleştirme noktasında kullanım potansiyeline sahiptirler. Günümüzde fiziksel modeller 3 boyutlu yazıcı teknolojisi sayesinde kolaylıkla üretilebilmektedirler. Ayrıca matematiksel denklemlerin verilen sınır şartları dahilinde oluşturulan matematiksel modelleri de şimdiye kadar hiç olmadığı biçimde kolaylıkla üretilebilmektedir. Bu tür uygulamalar, 3 boyutlu yazıcı teknolojisinin her geçen gün daha da iyileştirilmesi ve üretim maliyeti ile zamanının azaltılması ile artmaya da devam edecektir [11]. Üretilen bu modeller ile yüksek matematik, topoloji ve geometry gibi alanlardaki matematiksel düşüncelerin daha kolaylıkla ve daha anlaşılır biçimde ifade edilebilmelerine olanak sağlayacaktır [12].

$\mathrm{Bu}$ çalışmanın amacı, klasik mühendislik yöntemleriyle üretilmesi imkansız veya çok çok zor olan matematiksel modelden elle tutulabilir katı bir parçayı 3 boyutlu masa üstü bir yazıcı kullanmak suretiyle üretebilmektir. $\mathrm{Bu}$ üretilen parça gerek bir eğitim materyali olarak sunum amacina hizmet edecek ve gerekse soyut sadece sembol ve rakamlardan oluşan bir düşüncenin veya bir denklemin elle tutulabilen bir cisim haline dönüşmesine hizmet edecektir. 


\section{Eriterek biriktirme modellemesi (EBM) yöntemi}

Eriterek biriktirme modellemesi (EBM) (ingillizce orjinal ismi "Fused Deposition Modelling"- FDM) yöntemi bir katmanlı üretim teknolojisidir. Üretim için kullanılan malzeme genellikle acrylonitril butadiene styrene (ABS) termo plastik veya polylactic acid (PLA) termo plastiktir. Bu teknikte, termo plastik malzeme plastiğin erime sıcaklığının üzerindeki bir sıcaklığa kadar 1sıtılmış bir nozülden ekstrüzyona tabi tutulur. Ekstrüzyon sırasında 3 boyutlu yazıcının baskı kafası x-y düzlemi boyunca hareket eder. Nozülden akan plastik malzeme çok ince bir katman halinde bir önceki katmanın üzerine serilir. Tamamlanan her bir katmandan sonra parçanın üretildiği platform istenilen katman kalınlığı kadar $\mathrm{z}$ ekseni boyunca eksi yönde aşağıya iner. $\mathrm{Bu}$ işlem parçanın üretimi bitene kadar katman katman devam eder. Bu teknolojiyi kullanarak üretim yapan bir 3 boyutlu yazıcının çalışma prensibi Şekil 1 de görülmektedir. Eğer parçanın üretimi sırasında, yatayla $22^{\circ}$ den daha küçük açıya sahip yüzeyler mevcut ise bu durumda o yüzeylerin destek yapıları ile desteklenmeleri gerekmektedir. Parçanın destek yapısına ihtiyaç duyup duymayacağı yine MakerWare $^{\mathrm{TM}}$ katmanlara ayırma programı ile analiz edilmekte ve gerekliyse destek yapıları da hesaplanarak üretim sürecine dahil edilmektedir.

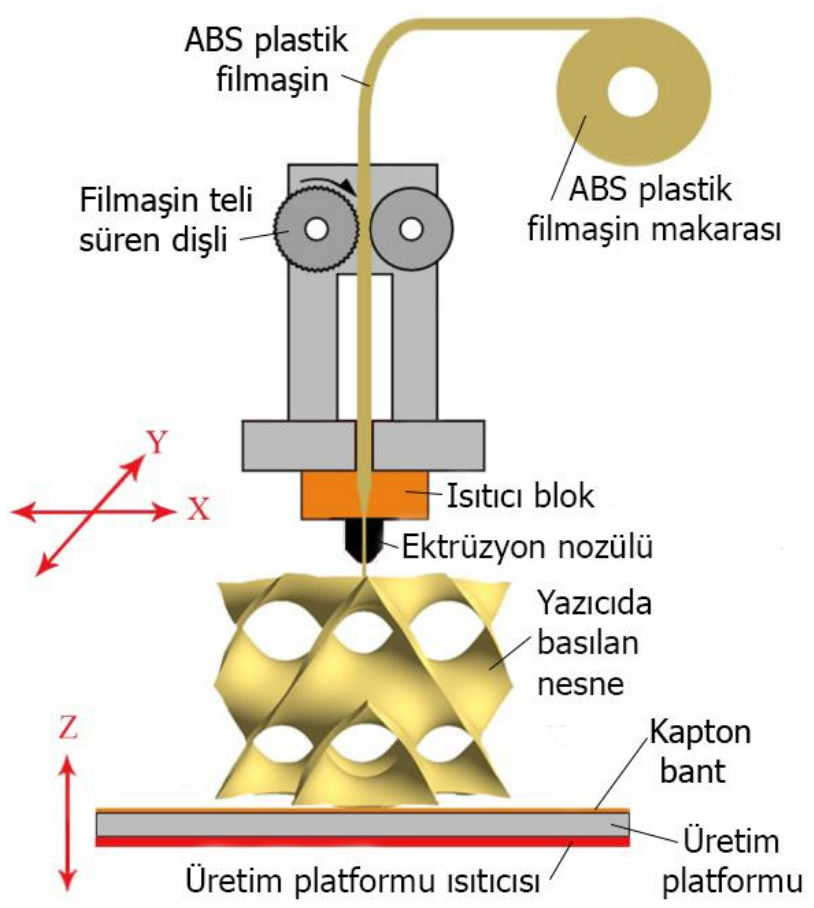

Şekil 1. Eriterek biriktirme modellemesi süreci (EBM) [13].

EBM süreci 3 boyutlu modelin katmanlara ayrılması işlemi ile başlar. Bu adımda sadece üretilecek katmanlar belirlenmez aynı zamanda ekstrüzyon kafasının hareketleri de hesaplanır ve eğer gerekliyse parçanın üretim platformu üzerinde bozulmadan durabilmesini sağlayacak destek yapıları da hesaplanır. Katmanlara ayırma ile ilgili olarak hesaplanan tüm bu değerler daha sonra 3 boyutlu yazıcının anlayabileceği dile yani "gcode" veya "x3g" dosya formatına dönüştürülerek ya bir SD karta aktarılır veya direk olarak bilgisayar aracılığıyla 3 boyutlu yazıcıya gönderilir. 


\section{3 Boyutlu EBM yazıcı ile üretim aşamaları}

3 boyutlu bir matematiksel modelin 3B yazıcıda üretimi sırasında 6 aşama mevcuttur.

Bu aşamalar;

1. Matematiksel modelin oluşturulması,

2. Katı ya da yüzey modelin elde edilmesi,

3. Elde edilen katı modelin "STL" dosya formatına dönüştürülmesi,

4. Katı modelin katmanlara ayrılması, ekstrüzyon başlığının ve üretim platformunun sirasıyla $x-y$ ve $z$ eksenleri boyunca yapacağı hareketlerin ve eğer gerekli ise destek yapılarının hesaplanması,

5. Modelin 3 boyutlu dijital üretim süreci,

6. Destek yapılarının parçadan temzilenmesi ve son yüzey işlemlerinin uygulanması (parlatma, boyama, temizleme vs.) [11,14].

\subsection{Matematiksel modelin oluşturulması}

Matematiksel modelin oluşturulması esnasında SourceForge tarafından geliştirilen, açık kaynak kodlu, K3DSurf v0.6.2 matematiksel modelleme yazılımı kullanılmıştır [15]. Bu yazılım matematiksel denklemleri kullanarak çok boyutlu yüzeylerin oluşturulmasını sağlamakta ve oluşturulan yüzeyin görsel olarak incelenmesine de olanak vermektedir. Yazılım aynı zamanda parametrik denklemleri ve izometrik yüzeyleri de desteklemektedir [16]. Yazılım 3 değişkenli $\mathrm{F}(\mathrm{x}, \mathrm{y}, \mathrm{z})$ fonksiyonunu verilen sınır şartları dahilinde istenilen artış miktarını da dikkate alarak hesaplayıp yüzeyi oluşturabilmekte ve bu yüzeyi görselleştirebilmektedir. Ancak yazılım denklemin sağ tarafının sıfıra eşitlenmesini gerektirmektedir.

Sonsuz periyodik minimum yüzeyler ilk kez Schwartz tarafından 1856 yılında araştırılmış ve matematik dünyasına duyurulmuştur [16]. Bu çalışmada ise bu yüzeylerden biri olan, kendi kendisini kesmeyen sonsuz periyodik minimum yüzey Schwartz D diğer bir adıyla Diamond denklemi kullanılmıştır [17]. Bu yüzeyin seçilmesinin nedeni ise, karmaşık yapısı nedeniyle, 3 boyutlu yazıcılar ortaya çıkana kadar, klasik mühendislik yöntemleriyle üretilememiş olmasıdır.

Şekil 2 de görseli verilen Diamond denklemi aşağıdaki gibidir;

$$
\begin{aligned}
F(x, y, z)= & \sin (x) \times \sin (y) \times \sin (z)+\sin (x) \times \cos (y) \times \cos (z) \\
& +\cos (x) \times \sin (y) \times \cos (z)+\cos (x) \times \cos (y) \times \sin (z)=\mathbf{0}
\end{aligned}
$$

Diamond denkleminin sağ tarafı sıfıra eşitlenerek (1) K3DSurf matematik yazılımına girilmiş ve denklem belirlenen sınır şartları arasında (2) değerler verilmek suretiyle nokta bulutunun elde edilmesi sağlanmıştır.

$$
x(-\mathbf{3}, \mathbf{3}), y(-\mathbf{3}, \mathbf{3}), z(-\mathbf{3}, \mathbf{3})
$$

\subsection{Matematiksel modelin yüzey veya katı model haline getirilmesi}

Diamond denkleminin yukarıda (2) belirtilen sınır şartları arasında oluşturulan matematiksel modeli 3 boyutlu yazıcıda basılabilmsei için ".obj" dosya formatına çevrilmek suretiyle elde edilen yüzey modeli Şekil 2 de gösterilmiştir. Bu işlem için de K3DSurf yazılımı kullanılmıştır. 


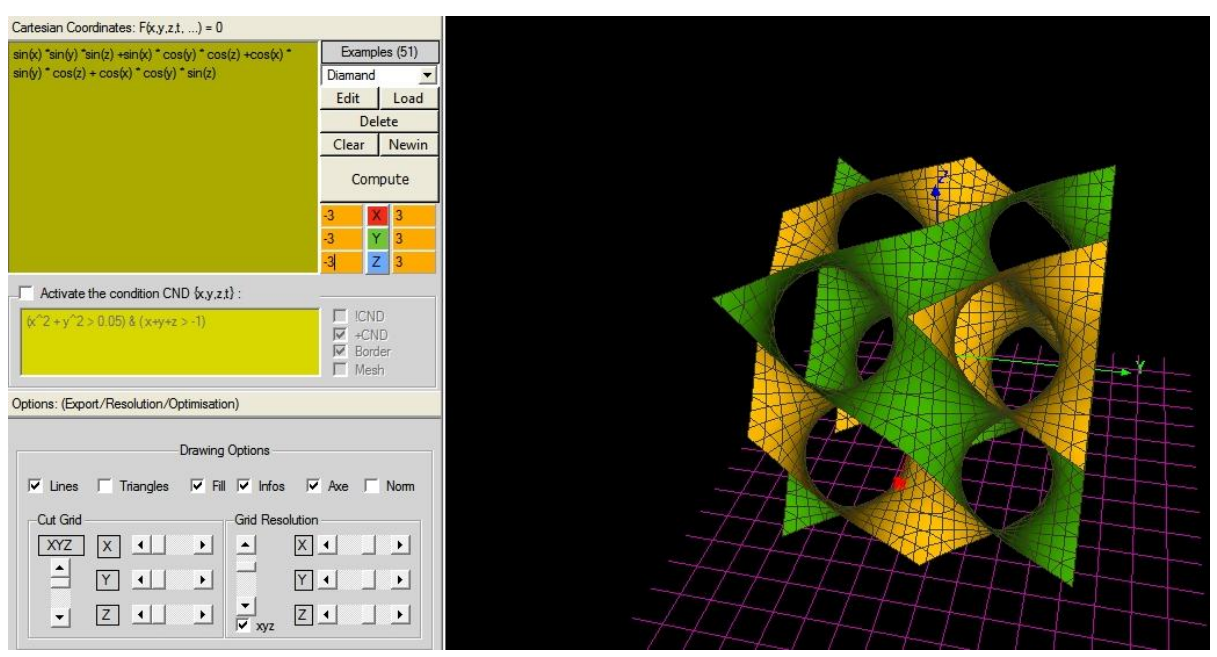

Şekil 2. Diamond denkleminin matematiksel modeli.

K3DSurf yazılımı konusunda deneyimi olmayan bir kullanıcı bile gerek bu denklemi modifye etmek veya gerekse sınır şartlarını değiştirmek suretiyle matematiksel modeli kişiselleştirebilir [18].

\subsection{STL dosya formatına dönüş̧ürme}

Matematiksel modelin kartezyen koordinat sisteminde nokta bulutu başarılı bir biçimde oluşturulduktam sonra K3DSurf yazılımı elde edilen bu noktaların bütün bir yüzeye dönüştürülmesini sağlamak üzere bu verileri “.obj” dosya formatına çevirir. MakerBot ${ }^{\circledR}$ firmasının MakerWare ${ }^{\mathrm{TM}}$ yazılımı hem ".obj" hem ".things" hem de ".stl” formatındaki dosyaları okuyabilmektedir [19]. Eğer oluşturulan yüzeye bir kalınlık verilmek istenirse bu durumda MakerWare ${ }^{\mathrm{TM}}$ yazılımı diğer yazılımlar tarafından daha yaygın olarak tanınan ".stl” formatına dönüştürme işlemini gerçekleştirebilir. STL dosya formatı yüzeyi kaplayan her bir üçgenin dışa doğru olan normaline ve köşe noktalarının koordinatlarına ait bilgileri içermektedir. Yüzeyi kaplamak için düzlemsel üçgen öğeler kullandiğı için STL dosya biçimi kavisli yüzeyleri tam olarak temsil edemez. Bu yetersizlik, üçgen sayısının artırılmasıyla hafifletilebilir. Ancak bu da dosya boyutunu ve işleme süresini arttırmaktadır [11].

\subsection{Katmanlara ayırma, nozül hareketlerini hesaplama ve destek yapılarının oluşturulması}

Matematiksel modelin katmanlara ayrılması aşamasında yine MakerWare $^{\mathrm{TM}}$ yazılımından faydalanıldı. Öncelikle modelin üretim platformunun üzerine minimum destek yapısı gerekecek şekilde oturması sağlandı. 3 boyutlu baskı zamanını minimize etmek platformun $\mathrm{z}$ ekseni yönündeki katman sayısına bağlıdır. $Z$ ekseni yönündeki katman sayısı ne kadar fazla ise katman kalınlığı o kadar ince ancak baskı zamanı da o kadar uzundur. Bu olumsuzluğa rağmen katman kalınlığının ince olması hem yüzey kalitesini arttırmakta hem de katmanların birbirlerine yapışmasını olumlu yönde etkilemektedir.

$\mathrm{Bu}$ aşamada sadece katmanlara ayrıma işlemi gerçekleşmez. Aynı zamanda hem plastiğin akacağı nozülün $\mathrm{x}-\mathrm{y}$ düzlemi boyunca yapacağı hareketler hesaplanır hem de modelin üretim platformu üzerinde bozulmadan dik durabilmesini sağlayacak destek yapıları da hesaplanır (Şekil 3). Şekil 3 de görüleceği üzere Diamond matematiksel 
modeli havada asılı kalan kısımlara ve bazı boşluklara sahiptir. Bu yüzden üretim sırasında parçanın bozulmaması için destek yapısına ihtiyaç vardır.

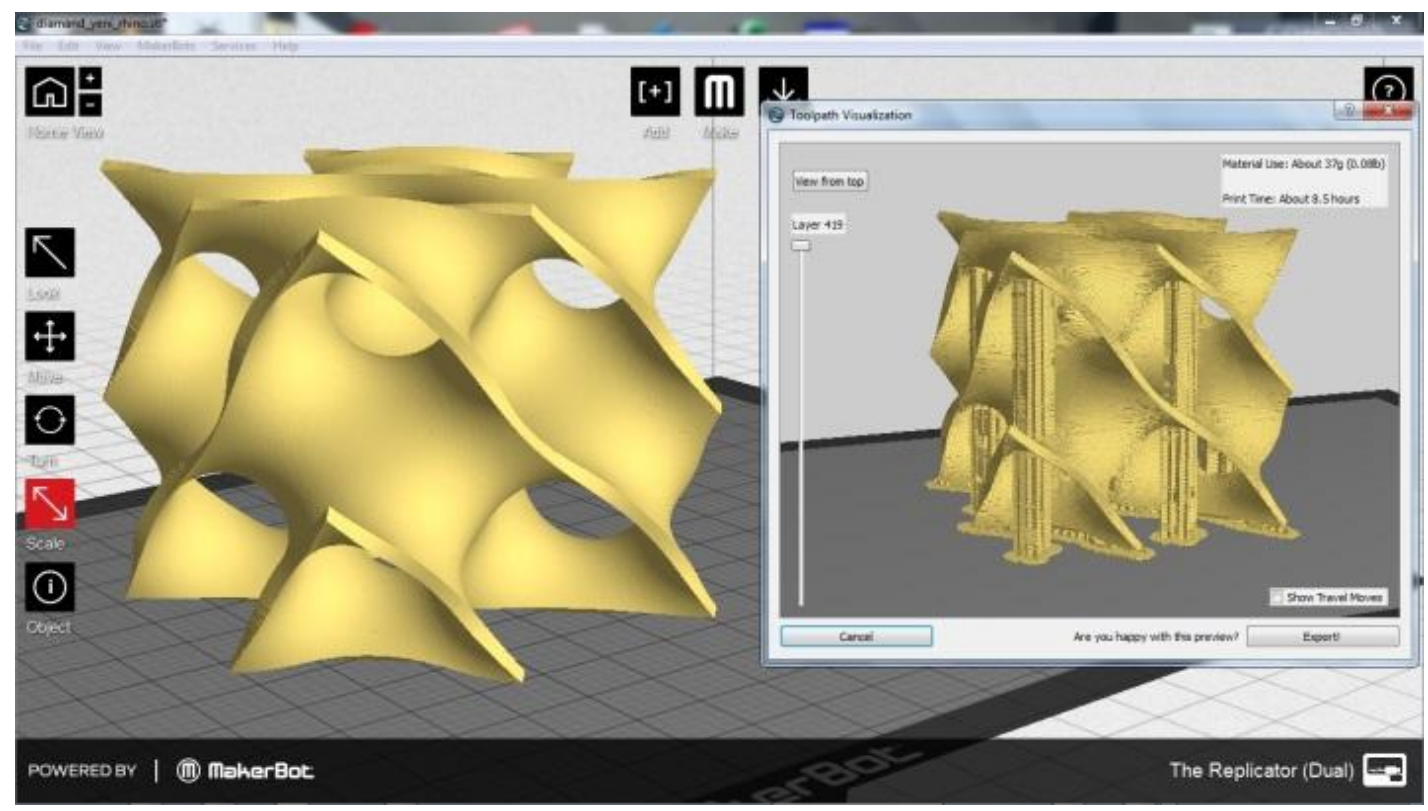

Şekil 3. Matematiksel modelin katmanlara ayrılması ve destek yapılarının hesaplanması.

Bu adımda aynı zamanda üretim sırasında kaç gram malzeme kullanılacağı, baskının ne kadar zaman alacağı ve kaç katmana ihtiyaç bulunduğu belirlenmekte ve her katmanda nozülün yapacağı x-y yönündeki hareketler de katman katman görsel olarak incelenebilmektedir. Yine bu aşamada istenirse parça ölçeklendirilmek suretiyle büyütülüp küçültülebilmekte, üretimin sağlıklı bir biçimde yapılabilmesi amacıyla paltform üzerine konulan nesnenin yönü de değiştirilebilmektedir.

Üretimi yapılan parça MakerWareTM yazılımı tarafından $150 \mu \mathrm{m}$ kalınlığında 419 katmana ayrılmış ve 37 gram malzeme kullanılacağı hesaplanmıştır.

\subsection{Modelin 3 boyutlu yazıcıda basılması süreci}

Balıkesir üniversitesi mühendislik fakültesi makina bölümünde mevcut eriterek biriktirme modellemesi yöntemiyle üretim yapan FlashForge Creator 3 boyutlu yazıcı ile şekil 4 de görülen Diamond matematiksel modeline ait elle tutulabilir katı model üretilmiştir. 3 boyutlu yazıcının basabileceği katmanların kalınlığ $100 \mu \mathrm{m}$ ile $250 \mu \mathrm{m}$ arasında değişmektedir. Şekil 4 de görülen parça $150 \mu \mathrm{m}$ katman kalınlığında üretilmiştir. Üretim malzemesi olarak acrilonitrilbütadiyen diğer bir adıyla $A B S$ $\left(\left(\mathrm{C}_{8} \mathrm{H}_{8}\right)_{\mathrm{x}} \cdot\left(\mathrm{C}_{4} \mathrm{H}_{6}\right)_{\mathrm{y}} \cdot\left(\mathrm{C}_{3} \mathrm{H}_{3} \mathrm{~N}\right)_{\mathrm{z}}\right)$ termo plastik kullanılmıştır. Kullanılan ABS plastik filmaşin telin çapı $1.75 \mathrm{~mm}$ dir. Üretim sırasında parçanın üzerinde inşa edildiği paltform ABS plastiğin daha iyi yapışabilmesi için üretim süresi boyunca $110{ }^{\circ} \mathrm{C}$ 'a kadar 1 sıtılmış ve platform sıcaklığ 1 sabit tutulmuştur. Üretim esnasında ekstrüzyon için kullanılan $400 \mu \mathrm{m}$ delik çapına sahip nozül ABS plastiğin düzgün bir şekilde serilmesini sağlamk için $222{ }^{\circ} \mathrm{C}^{\prime}$ a 1 sıtılmıştır. 3 boyutlu baski süreci sırasında ekstrüzyon nozülü X-Y düzlemi boyunca hareket ederken, üretim platformu da $Z$ ekseni yönünde hareket etmiştir. Matematiksel modelin baskı zamanı yaklaşık olarak 8,5 saat sürmüştür. 


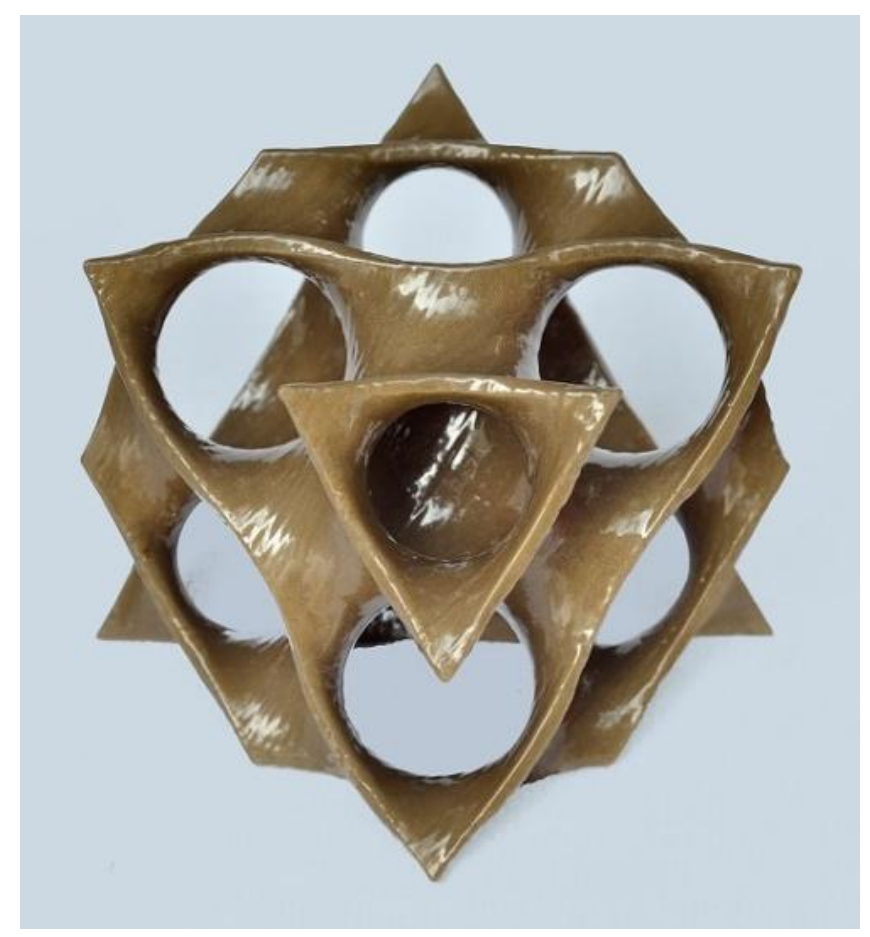

Şekil 4. Diamod matematiksel modelinin 3 boyutlu yazıcıda üretilmiş hali.

\subsection{Destek yapılarının kırılması ve parlatma işlemi}

Modelin üretimi sırasında destek yapılarına ihtiyaç duyulduğundan bu yapıların üretim sonrasında parçadan kırılarak uzaklaştırılması gerekmektedir. Üretilen bu parçadaki destek yapıları da bu şekilde parçadan alınmıştır. Ancak son zamanlarda geliştirilen suda çözünebilme özelliğine sahip PoliVinil Alkol (PVA) filamentler destek yapılarının üretiminde kullanılmakta ve destek yapılarının parçadan uzaklaştırılması işlemi parçanın suya atılması suretiyle sağlanmaktadır. Ancak bu durumda üretim yapılan 3 boyutlu yazıcının 2 adet ekstrüzyon nozülü bulunması gerekmektedir. Bu nozüllerden birinden ABS veya PLA termo plastik gelirken diğer nozülden PVA destek filmaşin tel gelmektedir. Şekil 4 de görülen parça üretildikten ve destek yapıları kırılarak parçadan alındıktan sonra dış yüzeyin görsel olarak daha etkileyici görünmesi amacıyla aseton buharına tabi tutularak parlaması sağlanmıştır.

\section{Sonuçlar ve tartışma}

$\mathrm{Bu}$ çalışmada alışılagelmiş mühendislik üretim yöntemleri ile üretilmesi nerdeyse olanaksız olan Schwartz D denkleminden yola çıkılarak K3DSurf matematiksel yazılımı yardımı ile belirlenen sınır şartları aralığında değerler verilerek nokta bulutu oluşturulmuş ve bu nokta bulutunun düzlemsel üçgen yüzeylerle birleştirilmesi suretiyle de kabuk yüzey modeli elde edilmiştir. Elde edilen bu bilgisayar modeli MakerBot® firmasına ait açık kaynak kodlu MakerWare ${ }^{\mathrm{TM}}$ yazılımı ile katmanlara ayrılmıştır. Katmanlara ayırma işlemi süresince iki şey dikkate alınmıştır: Birincisi ekstrüzyon nozülünün $\mathrm{x}-\mathrm{y}$ düzlemi boyunca yapacağ 1 hareketler, ikincisi ise modelin üretim platformu üzerinde hem dik durmasını hem de bozulmadan üretilebilmesini sağlayacak destek yapısının hesaplanması. Örnek çalışmada üretilen parça $150 \mu \mathrm{m}$ kalınlığında 419 katmana ayrılmış, 37 gram malzeme kullanılmış ve 8,5 saatlik bir üretim zamanı söz konusu olmuştur. 
Günümüzde düşük maliyetli masa üstü 3 boyutlu yazıcılar hızla gelişmekte her gün yeni bir malzeme türü ve yeni 3 boyutlu üretim teknolojileri bulunmakta bu ise kullanıcilara son derece karmaşık matematiksel modelleri üretme ile ilgili yeni ufuklar yaratmaktadır. Üretilebilecek parçanın katman kalınlığı artık EBM yöntemine göre üretim yapan 3 boyutlu yazıcılarda $50 \mu \mathrm{m}$ lar seviyesine düşmüştür. $\mathrm{Bu}$ da üretilen parçanın yüzey kalitesini ve düzgünlügünü doğal olarak daha da arttıracaktır.

\section{Teşekkür}

Yazar, BAP:2013/96 proje numaralı bu çalışmayı destekleyen Balıkesir Üniversitesi Bilimsel Araştırma Projeleri Koordinasyon Birimine teşekkür eder.

\section{Kaynaklar}

[1] Hull, C.W., Apparatus for production of three-dimensional objects by stereolithography. U.S.Patent 4,575,330 (Publication Date: 3/11/1986; Filing Date 8/8/1984). http://www.google.com/patents/US4575330. (10.06.2014).

[2] Lim, C.S., Chua, C.K. ve Leong, K.F., Rapid prototyping, World Scientific, Second edition, (2003).

[3] Cooper, K.G., Rapid prototyping pechnology, selection and application, Marcel Dekker Inc., (2001),

[4] Crawford, S., How 3-D Printing Works, http://computer. howstuffworks.com/3d-printing1.htm, (2013).

[5] Rosen, D., Gibson, I. ve Stucker, B., Additive manufacturing technologies, Springer, (2010).

[6] Knill, O. ve Slavkovsky, E., Illustrating Mathematics using 3D Printers, Cornel University Library, arXiv:1306.5599 [math.HO], (2013).

[7] Rosen, D.E., MakerBot industries to print anything and everything at one metro tech. retrieved from commercial observer, http://commercialobserver.com/2012/05/makerbot-industries-to-print-anythingand-everything-at-one-metrotech/, (2014), (05.09.2014).

[8] Rowan, D., 3D printing - An "Industrial Revolution in the Digital Age"? Retrieved from WIRED Business Future Shock http://www.wired.com/2011/05/3d-printing-an-industrial-revolution-in-thedigital-age/, (2011), (05.09.2011).

[9] Berman B., 3-D printing: The new industrial revolution. Business Horizons, 55, 2, 155-162, (2012), DOI:10.1016/j.bushor.2011.11.003.

[10] Segerman, H. 3D Printing for Mathematical Visualisation, The Mathematical Intelligencer, 34, 4, 56-62, (2012), DOI:10.1007/s00283-012-9319-7.

[11] Chapela, V. M., Percino, M. J., Calvo, F. D., Calvo, F. ve Trinidad, L., Manufacture of 3D Möbius-Listing Models with a 3D Printer, Proceedings of the World Congress on Engineering Vol I, WCE 2013, July 3-5, London, U.K. (2013).

[12] Slavkovsky, E.A., Feasibility study for teaching geometry and other topics using three-dimensional printers. M.L.A Thesis. Harvard University, (2012).

[13] Gür, Y., Additive manufacturing of anatomical models from computed tomography scan data, MCB: Molecular and Cellular Biomechanics, 11, 4, 249-258, (2014), DOI:10.3970/mcb.2014.011.249. 
[14] Marcincin, J.N., Marcincinova,L.N., Barna,J. ve Janak,M., Application of FDM rapid prototyping technology in experimental gearbox development process, Tehnički Vjesnik-Technical Gazette, 19, 3, 689-694, (2012).

[15] Taha, A., K3DSurf software package. URL:http://k3dsurf.sourceforge.net/. (04.01.2015).

[16] Schoen, A.H., Infinite periodic minimal surfaces without self-intersections, NASA Technical Note TN D-5541, (1970).

[17] Weber, M., Hoffmann, D. ve Hoffman J.T., Triply periodic level surfaces, http://www.msri.org/publications/sgp/jim/geom/level/library/triper/indexd.html (11.06.2017)

[18] Knapp, M.E., Wolff, R. ve Lipson, H., Developing printable content: A repository for printable teaching models, Retrieved from http://utwired.engr.utexas.edu/lff/symposium/proceedingsArchive/ pubs/Manuscripts/2008/2008-52-Knapp.pdf, (2008).

[19] MakerBot ${ }^{\circledR}$ MakerWare ${ }^{\mathrm{TM}}$ 3-D printing software, Retrieved from http://www.makerbot.com/support/makerware/ documentation/slicer/, (2014), (Retrieved 04.01.2015). 